\title{
SOBRE LA TRADICIÓN VALORATIVA EN CRÍTICA TEXTUAL: EL "AMANUENSE" DE QUEVEDO A LA LUZ DE UN POEMA MAL ATRIBUIDO
}

Para Alfono Rey, queredicia amige

En un reciente reconocimiento del avance experimentado por la crítica de la poesía quevedesca en los últimos decenios se observa, como contrapartida, que "no deja de ser inquietante comprobar en qué penumbra se hallan aún multitud de problemas textuales". tio maior de José Manuel Blecua, aunque "sin duda representa un avance enorme sobre todas las anteriores en el sentido bibliográfico y textual"'2, está libre de zonas de sombra cuya eliminación dependerá en buena medida de lo que se haga en ese doble sentido. Obra de transmisión tan compleja como la de Quevedo necesita, a la vez que un rastreo cada vez más severo de la documentación bibliográfica, un mayor afinamiento en la crítica de la otras fuentes textuales. El proceso de interacción que en tal sentido ha de llevarse a cabo para conseguir un corpus y un textus depurados se anuncia arduo, pero productivo. Las consideraciones que siguen son una muestra de ello: el hilo de una atribución desmentida nos conduce a la necesidad de revisar la banalizante y complicada idea del supuesto "amanuense" en algunos manuscritos quevedianos.

Con ejemplar modestia nos avisa el editor por antonomasia de Quevedo, a propósito de Las tres Musas últimas castellanas (Madrid, 1670), que "lo peor de Aldrete fue ahijar a Don Francisco bastantes poemas que no le pertenecían, iniciando así la larga serie de atribuciones que no terminará ni en mi edición de la Poesía original [1963] y es posible que en ésta [de 1969-1971] tampoco'"3. En las dos publica Blecua, en

1 Ricardo Senabre, "Hipótesis sobre la cronología de algunos poemas quevedescos", Homenaje a José Manuel Blecua, Madrid, 1983, p. 605.

2 James O. Crosby, Introducción a su ed. de Poesía varia de Quevedo, Madrid, 1981 , p. 27.

3 José Manuel Blecua, Introducción a su ed. de la Obra poética de Quevedo, t. 1, Madrid, 1969, p. xvii. En su anterior editio minor, que tuvo una importante reseña de J. O. CRosby - “A new edition of Quevedo's poetry", HR, 34 (1966), 328-337-, Blecua dio "entrada a más de un poema que no era de Don Francisco", como reconoce él mismo en la $3^{a}$ ed., p. xxxii.

- Emplearé en lo sucesivo las siguientes abreviaturas: 
efecto, bajo el rótulo de "Canción", un poema en silva que a partir de ahora debe engrosar el apartado de las obras espurias: Epitalamio en las bodas de una vejísima viuda, con cien ducados de dote, y un beodo soldadísimo de Flandes con calva original (BlecuA-A, pp. 631-636; BlecuA-B, t. 2, pp. 93-97). Las razones en que el admirado investigador apoya la autenticidad de ese texto - cuya procedencia no pudo certificar- resultan en verdad insuficientes: "El poema parece muy auténtico, a juzgar por el tema y el estilo. Incluso lleva al margen acotaciones semejantes a las que pone alguna vez González de Salas"' (Blecun-B, t. 2, p. 93). El criterio puramente literario muestra así una vez más, aun en manos de tan gran quevedista, su escasa fiabilidad para las labores de la crítica textual ${ }^{4}$. I a composición prohijada a Quevedo nada tiene de auténtica. Es copia, muy abreviada, de un poema del sevillano Rodrigo Fernán. dez de Ribera, que se publicó en pliego suelto en 1625. (La copia tiene 175 versos; el original 319, o sea casi el doble.) El único ejemplar de que tengo conocimiento está en la Biblioteca del Real Palacio de Madrid. Su portada reza; EPITALAMIO / EN LAS BODAS DE VNA / Vejissima Viuda, dotada en Cien ducados / $i$ un Beodo Soldadissimo de Flandes, / Calvo de nacimiento ${ }^{5}$. Lo reproduzco a continuación, modernizando la puntuación y la acentuación y desarrollando las pocas abreviaturas que hay (partícula que, $n$ final de sílaba); cuando la $I$ es mayúscula de $j$, escribo $J$; acentúo ó cuando significa 'oh', y á cuando significa 'ha'.

Asensio: Eugenio Asensio, Itineratio del entremés, Madrid, 1971

Blecua-A: Francisco de Quevedo, Obras completas, I. Poesía original, ed. José Manuel. Blecua, $3^{a}$ ed., 1971 (la I ${ }^{a}$ ed. es de 1963) (= editio minor).

Blecua-B: Francisco de Quevedo, Obra poética, ed. José Manuel Blecua, 3 tomos, Madrid, 1969-1971 ( = editio maior).

Crosby: James O. Crosby, En torno a la poesía de Quevedo, Madrid, 1967.

Epist.: Epistolario de Menéndez Pelayo y Rodríguez Marín (1891-1912), Madrid, 1935.

$O b-B A E$ : Obras de Quevedo en tres tomos de la $B A E$, editados el 1 y el 2 por Aure-

liano Fernández-Guerra y Orbe, y el 3 por Florencio Janer, Madrid, 1852 (t. 1), 1859 (t. 2) y 1877 (t. 3). Son los vols. 23, 48 y 69 de la $B A E$.

4 Suscribo en este punto las consideraciones de J. O. CrosBy, "Has Quevedo's poetry been edited? A review article", HR, 41 (1973), pp. 632-633: "Even though we do not have a normative guide to Quevedo's style or themes, the criterion of literary value can be employed, once other methods have been exhausted. Moreover, the literary judgments of a person of Blecua's long experience invite our respect: no one knows the texts of Quevedo's poetry as he does. . . The present state of bibliographical and historical documentation may well compel us to fall back on literary criteria. And we may find that today there exists no definition of Quevedo's style, language, and themes".

${ }^{5} \mathrm{~A}$ la hoja de la portada ( $\mathrm{v}^{\circ}$ en blanco) siguen cuatro signaturas $\mathrm{A}_{2}-\mathrm{A}_{5}$, cuatro sin signatura y una más en blanco. El Epitalamio comienza en la hoja A4. Al final se lee: "Con licencia, En Sevilla, por Luys Estupiñan / Año, 1625". El pliego está encuadernado, como núm. 10, en el vol. 39 de la serie Varios impresos (Bibl. de Palacio, III/6501). No figura en ninguna de las dos más extensas bibliografías de Fernández de Ribera, la que ofrece Cayetano Alberto De la Barrera en su ed. de las Poesías de Francisco de Rioja, Madrid, 1867, pp. 330-332, y la de José Simón Díaz, Bibliografía de la literatura hispánica, t. 10, Madrid, 1972, pp. 177-180. 


\section{A FRANCISCO FACHECO}

Invío a V.m. un monstro de la cudicia umana o un prodigio del carnal apetito, un non plus ultra de los disparates del mundo en dos colunas que, una por su vicio i otra por su edad, están tan cerca de su ruina. No an podido los encarecimientos dar alcance a la verdad en el mismo ser que la vi, por más que se an esforçado los desseos de esse himno nupcial que le hice. V.m. le autorize con su atención, pues no esperan otro fruto estas bodas, i éste será bastante para premio de mi trabajo. Guarde Dios a V.m. muchos años. De Sevilla, i noviembre I de 1625 años. Rodrigo Fernández de Ribera.

Con genio tal invocas a Himeneo

a la unión misteriosa

de esta copia de amantes prodigiosa, que en su assitencia creo

5 se juntó con las Gracias a bureo: quando tu Musa ordena

un desposorio en pena

de dos, de vivos sólo semejança, de Venus i de Baco pura chança,

10 delirio de Natura,

del rapaz Cupidillo travessura.

Descompuesto a tu canto ver espero

el Catón más severo,

i depuesto el semblante zahareño

15 el más estoico ceño.

I espero, más, que en viendo sus traslados, se han de reír de sí los desposados.

Ella, que ve acercarse su fin tanto, á de alegrarse viendo

20 que si puede vivir, es en tu canto;

i él, que si vive es quando está beviendo,

holgará que su dama

para sus brindis pueda ser mojama,

i desseará, contento,

25 que un lagar sea el lugar del casamiento, adonde ia otra vez tiene provado que la passa i la uva se an casado; i al fin verá que tú lo has redimido, si de su sueño no, de el del olvido. 
que espero ia que el vino

locos de risa á de hacer salado.

5 De suerte as animado

los huessos que celebras, que nos deja

eterna tu instrumento aquesta vieja.

Mil mocedades, que invidiarla veo, por tal vejez trocaran sus edades;

$10 \mathrm{i}$ de tu voz lo creo,

aunque es milagro en todas mocedades.

Tan cuerdo persuades

lo que festivo pintas, que estas bodas

todas son risa, i escarmiento todas.

15 Si él previó que en tu pluma avía su fama de volar a la luz tan felizmente,

no cudicia se llama

su acción: presunción sí, quando valiente

se abraça a un inclemente

20 Furia, con quien atado noche i día, si ella parece hiscal, él tendrá lía.

Gravementre tu voz suena jocosa, pero Vate te admiro i temo Orfeo: que esta vieja invidiosa

25 podrá, si se reviste de Lieo, como sin duda creo (u de su esposo), con vergüença poca, lo que vieja recibe, pagar loca.

\section{[EPITALAMIO]}

Ven, Himeneo, ven; onrra este día, no qual sueles, bañado en alegría, pero de orror compuesto.

A este que funeral á de ser presto,

5 con pie siniestro assiste, unión de enima i casamiento en chiste, que, desmintiendo siglos, se acomoda a parecerse a boda. No tardes, o contigo

10 un ataúd traerás, Mancebo amigo; que si tardas, sospecho que en él para la nobia traerás lecho, $i$ al infausto velado piadoso escusarás de esse cuidado.

15 De antorcha, u de torzida, luz traerás prevenida: que no hallarás con poca, si el sí le buscas, lo que en ella es boca. No te cargues de tea,

20 que en ella tendrás mucho que lo sea. 
En la llegada te encargara el tiento, a no saber que avisos de su aliento te librarán bien antes de dar en sus narizes garamantes.

25 Pero, con todo esso, no entres con pie desnudo, que ai huesso que, de agudo, tiene cosas de azero, siendo huesso. Buscaron cien ducados

30 bolsa a quien ser de un gato trasladados; nunca dieron con ella, mas dieron con buen cuero de que hacella. Dos costales, de huessos i dinero, su cepo i su carnero

35 muchos años buscaron, i por cepo i carnero un lobo hallaron. Esta entre mil pellejos alma en pena (sólo en su boda para flauta buena) passar quiere sus quartos o chanflones

40 entre algunos doblones, i ver la luz a sus dineros deja; sus reales da a saco. ¡Ai de ti, protovieja! Si Venus toda se resuelve en Baco

45 i hace la razón en sinrazones, daros á un San Martín mil Santiagos. Tu vida toda (jai triste!) será tragos, como toda la suia vejaciones; pero será ventura,

50 pues no te afrentarán la dentadura.

A la Invidia me dice que parece tu figura, el que más me la encarece; mas si la Invidia fueras, por lo menos mordieras.

55 Las niñas de los ojos te an faltado, que dicen que asta aquéssas te as chupado, i que de tus quijadas escapan tus palabras lastimadas. Cobrará por sus tercios tu obligado

60 tus años a ducado; mas que le quede aún siento ducados que cobrar, con llevar ciento. dicen todos que, vana en tus dineros, llevas tu esposo en cueros;

65 más ¿qué importa que él vista, coma i beva, si en carnes, aunque quiera, no te lleva?

Dicen que no llovía Dios sobre cosa suia, i no te assombre, que fue porque de noche ni de día

70 agua le dio jamás encima a este ombre. 
Tu dote va en vellón, cosa admirable; dicen que vendrá a ser oro potable en poder de tu esposo, soldado a muchas pruevas animoso,

75 pues assí se averigua con hacerse mitad de una estantigua, i furioso arremete a terrapleno tal sin buen mosquete. ¡Ai Dios, qué orror, qué miedo

80 será en el lecho i sin modestia verte! Qué valor, qué denuedo será el que induzga al lado de la Muerte! Sin duda que quemarse, persuadido quiçá de algún estraño

85 espíritu, tentó; i, por menos daño, eligió aqueste mísero al casarse.

Como si no pudiera el vino hacer hoguera, i más en quien se casa, doña Eco,

90 porque fue vid, con un sarmiento seco.

Como si entre tus pieles no avrá horcas, saetas i cordeles, i quantos por delitos se dan castigos a ombres infinitos;

95 pero de todos ellos tu velado io sé que á de elegir el de encubado. ¿Qué será verte en cueros, doña Hebra? En ti, como en culebra tu mosca debió andar, dote precito, 100 que nace oi a morir como mosquito. Pero, aunque es prodigioso atrevimiento el hacer tal pesquisa, ¡quién te viera en camisa! mas confessado, i hecho testamento.

105 ¡Quién te viera en pelota, te tocara una mano! pero con las insignias de cristiano, $i$ armado de una cota $i$ otra cota, i aun me quedara miedo

110 de verme atravessado de algún dedo. ¡Laberinto de rugas, entre quien son Centauros tus pechugas! ¡No Quinta Angustia, angustias sí noventa, guadaña de la Muerte más hambrienta!

115 En lo antiguo i sutil no avrá persona que, acomodada al lado de aqueste gran soldado, no te juzgue en sus lides por Tizona: $i$ io digo que ierran, pues su espada 120 siempre á de ser Colada. 
No lleva él sobrehuesso, mas muchos que roer, io lo confiesso. Quando enojada sus agravios tomes, no le podrás mascar si te lo comes.

125 que aunque irritarte intente, no le podrás mostrar dientes, ni aun diente. $\mathrm{Su}$ sobrecarga eres, no carga, como las demás mujeres; que nuestro desposado

130 anduvo siempre, aun sin casar, cargado. Que guardes tu marido te aconsejo con la misma atención que tu pellejo. Cien Pascuas le darás con que le agrades, que bien podrás, i todas Navidades.

$135 \mathrm{Si}$ el, con que te $1[\mathrm{e}]^{*}$ das, es amor puro, su gusto te asseguro, que nunca vio al pesar ni a la fortuna, porque aguan los placeres; i siendo aquesto assí, sin duda alguna

140 que para no tener pesar lo quieres. Dime, ¿a qué cimeterio hiço este ombre, sacándote, adulterio? ¿Es maldiciente, di? que de esta suerte no le dejará huessos a la Muerte.

145 Mas su calva i tu ossario, si el matrimonio es cruz, serán Calvario. Si él huie de la carne, tierra harta á puesto en medio, pues tras ti se aparta; pero, sin levantarle testimonio,

150 ¿cómo huirá contigo del demonio? que del mundo está cierto que podrá quien se casa para muerto. Del requiebro de Adán sola una parte á de poder tocarte,

155 que es la de "huessos de mis huessos". Déos el cielo carne, o máteos los desseos. Él se casa (perdóname el decillo) con un Martes que es Miércoles Corbillo; en él tu vista lo carnal destierra,

160 i entrará la memoria de ser tierra; mas quien de la agua fue tan enemigo, ame la tierra en que dará consigo, que agora, si caiere (igran consuelo!), en ti dará, como antes en el suelo.

$165 \mathrm{Al}$ menos con tal dueño tierra serás de mui gentil vidueño, i él contigo (¡ó atanor de melecinas!) tendrá tierra que echar a sus mohinas.

\footnotetext{
* El texto dice la.
} 
También para sus manchas te imagino

170 bucna, que tierra en fin serás de vino.

Tendrá aparejo harto,

en tu edad i en tu gesto,

de padecer miserias en el sesto

i de cumplir con méritos el quarto.

175 Casamiento por cierto de respeto, que él es ia avuelo, i puede ser tu nieto. $\mathrm{Si}$ impulso de ser madre buscar te hiço a tus antojos padre (¡ó tú deste rozín esposa o traba!)

$180 \mathrm{i}$ a las segundas bodas te irritaba*, del matrimonio en vano ve aprovechas, pues si engendrare en ti, serán sospechas; en vano lo cudicias, pues si concibes dél, serán malicias.

185 Mas por esto no es justo que te meses: que si no en ti, de ti, si lo procuras, podrá hacer tu esposo mil criaturas, todas de a nueve meses.

Parece que la Muerte se á olvidado

190 de ti ia, doña Edad, doña Vestiglo; o te quiere casar con algún siglo tras esta boda en que reinó el dorado. Tome con tiento, si es cristiano i pío, possessión de ti amarga:

195 que en ser sin fruto i larga, pareces esperança de judío; mas eres, con verdad mui conocida, la cristiana más vieja desta vida.

O es tu vida de estopa, o es de arambre.

200 o tu cuerpo las Parcas por estambre van hilando sin duda, i aun toman las tareas a remuda. ¡Ai, seca i larga más que la de España, nobia espiritual, Siringa en caña!

205 Eres, por ecelencia,

Fenis de la vejez, la quintaessencia, vieja superlativa en quien la Muerte dizen que está viva i anda la Vida muerta,

210 vieja consumadíssima i esperta, de vieja graduada, parienta mui cercana al primer nada. Si es grado el ser casado, él lleva gran vejamen en su grado.

$215 \mathrm{Bien}$ io le aconsejara 
que [a]1* Jordán, doña Estatua, te llevara; mas será desvarío, que te querrá más vieja que ir al río, como en sus aguas, al entrar, no vea

220 lo que en las de Caná de Galilea; pero, si no en Caná, por las mañanas avrá de amanecer bañado en canas.

Oi el que de las Dunas sus armas sacó aiunas,

225 las ceba (¡ai de él!), sin cólera precissa, no en Brabante o Ruán, pero en la Frissa, Ambos lleváis ganancias: que tú hallaste tus Flandes i él sus Francias. Mira no te lastime

230 quando a este Marte abraças, porque siempre está armado de coraças. Pero quando amoroso se te arrime, ¿quién no dirá que Amor ia de guerrero quiere en los dos finarse,

235 pues que llega a pegarse con los huessos el cuero? Sola tú en este suelo con un lobo pudieras atreverte, porque no tienes carne ni rezelo

240 de que ia** sino huessos que lamerte: cosa de ti con gusto pretendida, para tener de moça el ser lamida Si por no ser tus huessos de tozino no dieres salsa al vino,

245 contra él darás antídoto aprovado, pues eres toda tierra, i de finado. Tienta la carne al ombre, de más eroico nombre (¡estrañas confusiones!).

250 No son las de tus huessos tentaciones: estímulos serán, serán heridas, i más si dan de codo, i resistidas. Dígalo tu figura, a quien, por tentación menos segura, 255 no sé cómo el demonio, en partes muchas del iermo, no introdujo a tantas luchas: no para los assaltos sensuales, sino, de las fantasmas infernales, por la que con más prisa

260 o infunde orror o descompone a risa: que para tantos daños, cien siglos á que estabas de cien años.

* El texto dice $e l$.

** Sic en el impreso (ià), pero el sentido pide aia'haya'. 
Cierva eres en vivir, más ¡ó dichoso aquel que siendo de una cierva esposo

265 en tiempo tan protervo, puede vivir tan lejos de ser ciervo!

Avrá en tu lecho amigo ocio de eternidad, caduco abrigo, donde, por más que oi ablas,

270 tus huessos callarán como sus tablas. Suçurrador enjambre, i no de Amores, de penas sí i dolores, verás mustio pender sobre tu cama. Pero entre tantos humos, i sin llama, 275 ¿qué hará Cupidillo, blando rapaz i ciego? si no es que en ti, por seca, enciende fuego de su harpón al toque más senzillo. $\mathrm{Ni}$ el molesto cuquillo

280 ni la infame corneja sobre tu techo vuelan agoreros, que do la nobia es vieja, sobrarán justamente otros agüeros. Dime ( $¡$ assí felizmente te suceda!)

285 si es de tu edad acaso tu moneda, que te tendrán con ella por dormiente, bien que correr dinero vimos sin ésta alguna vez de cuero; aunque, por lo que tiene esso de fuente,

290 ni aun la moneda querrá ver corriente. la mi furor refrena tu respeto, péssima moradora del Parnasso: que siendo epitalamio el que prometo, a sátira me voi mi passo a passo.

295 Quedáos a Dios los dos, que en los dos veo muerto de risa o miedo a Himeneo, que assiste a la batalla en medio ia de Ossuna i de Caçalla. ¡Mil años os gocéis libres de daños!

300 Mas él será el que en ti goce mil años, su doña Essalación, doña Selecta, doña Dificultad por línea recta. I por ti este mi canto dichoso podrá ser que viva tanto,

305 que de oi en quatro mil años cabales celebren estas bodas bacanales, en su lengua o la estraña, con versos monosílabos festivos, poetas matasanos que a porfía

310 harán de mí, en la tuia, notomía, si agora pretendieren (¡vil haçaña!) no doctos, sino esquivos, 
curarme con herirme en cueros vivos; qual si el ensalmo de Monturque i Rute

315 dejara aun cicatrizes en la cute, i io en defensa mía no uviera en ti obligado una Harpía, $i$, en invidia de Oracio u de Petrarca, mi Mecenas no fuera este Monarca.

FIN

Los preliminares del pliego suelto no dejan resquicio de duda en cuanto al verdadero autor del Epitalamio, de manera que éste habrá de sumarse a la aún no coleccionada obra poética de Fernández de Ribera $^{6}$. Por otra parte, es evidente la enorme superioridad del texto aquí reeditado sobre el atribuido a Quevedo?. Problema subsidiario en esta nueva perspectiva es el calibrar la relación que hay entre el texto de Fernández de Ribera y el pseudo-quevediano. He dicho que éste es "copia abreviada" de aquél, pero la cuestión no es tan simple. Diré rápidamente que, siendo poco verosímil que el manuscrito pseudoquevediano proceda directamente del impreso de 1625, me inclino a pensar que la fuente no es el Epitalamio impreso, sino un "borrador" o versión manuscrita anterior a 1625 (y que el autor retocaría y ampliaría después $)^{8}$.

Esta cuestión, en todo caso, le incumbe al futuro estudioso del satírico sevillano. Lo que a mí me interesa es reconsiderar el fundamento textual de la atribución a Quevedo. Blecua, que primero dijo que nuestra poesía fue "publicada por Astrana Marín según una copia del amanuense de Quevedo en poder de don Luis Valdés" (BLECUA-A, p. 636), después matizó: "Publicada por Astrana Marín, según un ms. de la biblioteca

6 Véase un elenco en la Biografía del poeta sevillano Rodrigo Fernández de Ribera y juicio de sus principales obras, por JoAquín Hazañas y LA Rúa, Sevilla, 1889, con los agregados de mi "Contribución al estudio de un poeta barroco. (Comentario y edición de tres obras inéditas de Rodrigo Fernández de Ribera)", AnMal, 4 (1981), 115-141.

7 Véanse, como ejemplo, los vs. 59-62. Su sentido es diáfano: "Tu marido (tu obligado) va a hacerse pagar sus servicios militares (sus tercios) cobrando un ducado por cada año que tú tienes; aunque creo (siento) que en ese caso le vas a salir debiendo, pues tu dote es apenas de cien ducados' (o sea que la vieja es más que centenaria). En la versión atribuida a Quevedo, este pasaje es ininteligible: "Cobrara yo sus tercios, tu obligado / tus años a ducado; / mas que le quede aun ciento / ducados que cobrar, con llevar ciento"'. El lector puede confrontar así los vs. 21-24, 32-36, etc., etc. El único caso en que el texto pseudo-quevediano mejora el del pliego suelto está en el v. 180: invitaba parece preferible a irritaba.

8 En el texto pseudo-quevediano se omiten los vs. 19-20, 25-28, 45, 48, 67-70, 79-110, 135-140, 143-144, 169-170, 185-202, 229-266, 271-283, 291-294 y 301-319. Los vs. 203-222 aparecen trasladados a continuación del 228. Después del v. 270, la versión atribuida a Quevedo trae dos versos - "a cuyo infame yelo / martas aplicará de Coca en pelo" - que no figuran en el pliego suelto. El manuscrito pseudo-quevediano lleva unas apostillas marginales que pueden leerse en las eds. de Blecua. 
de don Luis Valdés, "copia del amanuense de Quevedo"" (BLECUA-B, t. 2, p. 93). Cambio expresivo: en vez de aceptar in toto la tradición valorativa sobre un manuscrito que no ha podido consultarse, ahora se distingue entre el poema en sí (juzgado auténtico por razones de coherencia con la vena satírica de Quevedo) y el carácter del vehículo material, calificado sólo con la cita que responsabiliza a su primer editor ${ }^{9}$. No obstante, en el hecho mismo de incluir el poema entre los de Quevedo alguien tan poco entusiasta de la indiscriminada taracea de Astrana Marín (cf. Blecun-A, pp. Ixxxvi-lxxxviii, y BlecuA-B, t. 1, pp. xxxi-

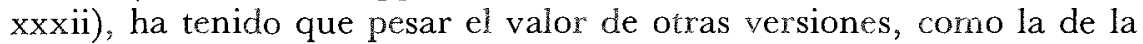
Epistola satírica y censoria (Blecva-B, t. 1, pp. 294-301), ahijada a la misma escritura del amanuense.

Th ese volumen que prodamaba pormposamente desde su portada ser "edición crítica con más de doscientas producciones inéditas del príncipe del ingenio" -y que, "sean cuales fuesen los defectos críticos, los silencios y ocultaciones, prestó un señalado servicio movilizando un inmenso caudal de escritos y documentos"' (Asensio, p. 198)--, Astrana Marín colocó con pasmosa seguridad etiquetas de autografía y rúbricas del amanuense a diferentes textos manuscritos ${ }^{10}$. El hecho desde luego sorprende, pero haría falta una actitud hipercrítica para que la sombra de la duda dejara de planear en casos como los que reaparecen en las ediciones de Blecua, máxime cuando se trata de materiales que no han podido ser confrontados de nuevo. Por fortuna las hojas en que se copiaba la sátira contra Francisco Morovelli de la Puebla, de la que "dijo Astrana que el manuscrito era de letra del amanuense de Quevedo" (igual que siempre, sin explicar "cómo había llegado a formarse tal opinión"), vinieron a manos de Crosby, el cual nos certifica que en ellas "no consta indicación explícita de autor ni de copista", salvo que "en la carpeta de papel moderno dice una nota, igualmente moderna, que se trata de un manuscrito autógrafo de Quevedo". Esta incongruencia de filiaciones en cuanto a la escritura de un texto que carece de notación original pero que, según concluye su actual poseedor, "difiere marcadamente de la de Quevedo" (Crosby, pp. 91-92) ${ }^{11}$, nos pone en camino de averiguar la génesis del misterioso "amanuense".

9 Quien anota: "Inédito, ms. del siglo Xvir, en la biblioteca de don Luis Valdés. Copia del amanuense de Quevedo, que transcribimos literalmente"' (Obras completas de Quevedo, Obras en verso, ed. Luis Astrana Marín, Madrid, 1932, pp. 112-113). En el Registro de manuscritos, donde figura con el núm. 50 (ibid., p. 1355), reitera: “Bibl. de Valdés. Ms. del siglo XVII, letra del amanuense de Quevedo". El Epitalamio y la valoración del manuscrito se reproducen en Obras completas. Obras en verso, ed. F. Buendía, Madrid, 1967, pp. 477-479.

10 Sobre todo a los comprendidos entre los núms. 40 y 77 , y casi siempre con la localización “Bibl. de Valdés" (ed. cit., pp. 1355-1357). La edición de Felicidad Buendía que vino a sustituir - o a empeorar - la de Astrana Marín, depende de éste en las descripciones (ed. cit., pp. 1213-1215).

11 En realidad, la copia muestra rasgos distintos por la intervención de un "corrector"' (GROSBY, p. 51). 
Astrana Marín es un "zahorí que no destapa los secretos de su vara" (Asensio, p. 232). Muy bien, pero cabría añadir que ni él controlaba el informe legado de textos sin identificar y valoraciones sin justificar que llegó a sus manos. La masa discontinua y plagada de contradicciones constituida por los papeles que le facilitó Luis Vidal y Alberti, sobrino de Aureliano Fernández Guerra, no le permitía ir más allá. El mejor de los quevedistas del siglo XIX no parece haber avanzado lo suficiente en el estudio de la lírica como para dejar "preparada" su "edición crítica", según creía en 1895 Menéndez Pelayo (Epist., p. 23). El volumen tercero que la $B A E$ dedicó a Quevedo y contiene su poesía no aparece bajo la firma de Fernández Guerra: la nota editorial explica que los papeles estuvieron esperando quince años, "al cabo de los cuales se confió a otro literato la tarea de coleccionar el presente tomo" ( $O b$ $B A E$, t. 3, p. iii). La tardanza se explica si, con ayuda de las cartas cruzadas entre Menéndez Pelayo y Rodríguez Marín ${ }^{12}$, consideramos "todo lo que [Fernández Guerra] tenía trabajado sobre la parte poética de las obras de Quevedo" (Epist., p. 15) 13. El alijo que formaban "las composiciones y las notas y las papeletas de don Aureliano" resultó un rompecabezas de difícil manejo (Epist., pp. 66, 87, 257, etc.). Para muchos poemas inéditos, "especialmente satíricos y de burlas", no era clara ni la autenticidad ni la procedencia, y los preparadores, cuyo método de trabajo distaba de ser riguroso ${ }^{14}$, tuvieron que acudir continuamente a cotejos y presunciones (cf. Epist., pp. 113, 190, 216). Bien podemos imaginar que Astrana Marín, con menos escrúpulos y más prisa, se limitó a dar coherencia superficial a la masa, sin "poner en orden los materiales. . . ni identificar la fuente de los textos"'15. Alguna vez (como en la sátira cuyo manuscrito ha estudiado Crosby) ampliaría por su cuenta la presencia del amanuense ${ }^{16}$, prolongando así la labilidad inventiva con que el erudito del siglo xix había clasificado y valorado los textos.

12 Referentes a la luego interrumpida edición que auspició la Sociedad de Bibliófilos Sevillanos: Obras completas de Don Francisco de Quevedo Villegas, ed. crítica, ordenada e ilustrada por D. Aureliano Fernández-Guerra y OrBe, con notas y adiciones de D. Marcelino Menéndez Pelayo, 3 tomos, Sevilla, 1897-1907.

13 En las fechas de esta carta y de la que corresponde a la cita anterior, Menéndez Pelayo aún no había manejado "los papeles" que poseía Vidal y Alberti, lo que explica su entusiasmo por ese "gran trabajo, que quedó truncado por culpa del viejo Rivadeneyra",.

14 Como ejemplos de arbitraria manipulación de los textos véanse estos pasajes de cartas de Rodríguez Marín: “Cotejando varias copias y dándole mil vueltas he llegado a la siguiente lección que someto a usted para que, si le parece bien, se imprima de esta forma" (Epist., pp. 188-189); "En cuanto a variantes, si a usted le parece bien, yo las sacaré para darlas al impresor con el texto, todo a reserva de que usted, como hasta aquí, añada, quite y enmiende, tal como convenga"' (p. 239).

15 J.O. Crosby, en su ed. cit. de Poesía varia de Quevedo, p. 27.

$16 \mathrm{Su}$ incapacidad técnica para diferenciar la letra del amanuense respecto de cualquier autógrafo se manifiesta en el apéndice "Modo de escribir de Quevedo: su especial puntuación y ortografía”, pp. 524-527 del Epistolario completo de Quevedo, ed. L. Astrana Marín, Madrid, 1946. 
"El reconocimiento de la autografía de grandes escritores es una de las cuestiones más importantes que pueden plantearse al investigador literario. Sin embargo es uno de los temas menos tratados. Lo corriente es que el investigador se fíe de su instinto y su memoria, que se fije en uno o dos rasgos que considera característicos, con vagas apreciaciones sobre el curso general de la letra". Estas consideraciones de Dámaso Alonso, motivadas por cierto juicio de La Barrera sobre una nota marginal tomada como autógrafa de Góngora ${ }^{17}$, son plenamente aplicables a quien hacía suyo el aserto de Gallardo sobre que "las obras de los grandes artistas para ser reconocidas por suyas no han menester la vulgar diligencia de ir marcadas con su nombre; se lee tan claro éste como en las letras los rasgos de la pluma"18. Fernández Guerra, "arrastrado por su entusiasmo de coleccionista e incapaz probablemente de discriminar entre letras generacionales semejantes" 19 , tenía invencible proclividad a considerar autógrafos los manuscritos que manejaba, sobre todo si eran propiedad suya o de bibliófilos de su círculo. En ningún caso consta que la seguridad de sus diagnósticos de autografía haya sido precedida no ya por una investigación sistemática, sino siquiera por el razonable manejo de un referente: eran resultados apodícticos del más puro capricho ${ }^{20}$.

En el caso de Quevedo, la variedad y riqueza de la cantera documental de que dispuso Fernández Guerra impedía la proliferación de "autógrafos" 21 . Entonces hizo su aparición el "amanuense", cuyos productos tenían casi el valor del autógrafo. El cómodo expediente resultaba útil en dos frentes: revaloraba los textos como piezas bibliofílicas y le daba holgura al preparador a la hora de justificar preferencias. Rela-

17 D. Alonso, "Góngora no llamó hidiota a Lope", artículo recogido ahora en Obras completas, t. 6, Madrid, 1982, pp. 323-330.

18 Aureliano Fernández Guerra, "Noticia de un precioso códice de la Biblioteca Colombiana, con varios rasgos inéditos de Cetina, Cervantes y Quevedo", publicada en el Ensayo de Gallardo, t. 1, col. 1260. "Distinguirá los rasgos de su pluma en cuanto fije en ellos la vista", glosa unas líneas adelante. El apócrifo que con tal procedimiento añadió a la obra cervantina en esa ocasión sería seguido de otros textos espurios. Cf. Juan Bautista Avalle Arce, "Atribuciones y supercherías", en el vol. colectivo Suma cervantina, Londres, 1973, pp. 399-408 (véanse los núms. 3, 4, 8, 18, 30, 31, $37,38,54$ y 61$)$.

19 AsEnsio, pp. 226-227, a propósito de los mss. de Los refranes del viejo celoso y El hospital de los mal casados, entremeses que en 1932 publicaría Astrana Marín con la misma valoración. En opinión de quien ha publicado "los textos íntegros, transcritos con esmero", hasta la autoría de Quevedo "queda en tela de juicio como muy problemática" (CROSBY, pp. 76-79 y 205-227).

20 Miguel Artigas, Don Luis de Góngora y Argote. Biografía y estudio crítico, Madrid, 1925 , pp. 225-226, planteó serias dudas sobre sus indicaciones de autografía en manuscritos de Góngora, "comparando la letra con las páginas indudablemente autógrafas que he alcanzado a ver".

21 Cf., sin embargo, Crosby, pp. 73-94 ("Manuscritos reputados por autógrafos"). Para la autografia de Quevedo, véase la ejemplar edición que ALFONSO REY nos ofrece en Virtud militante, Santiago de Compostela, 1984, pp. 59-68. 
cionados con el "amanuense" figuran los siguientes manuscritos en el "Catálogo de las obras de Don Francisco de Quevedo Villegas, clasificadas y ordenadas" por Fernández Guerra ( $O b-B A E$, t. 1, pp. lxxxiii-xc):

7. Mundo caduco y desvaríos de la edad. Existe de letra del amanuense de Quevedo.

14. Descifrase el alevoso manifiesto con que previno el levantamiento del duque de Berganza con el reino de Portugal, don ...gustín Manuel de Vasconcelos. Letra del amanuense de Quevedo y apostillas de éste.

16. Panegírico a la majestad del rey nuestro señor don Felipe IV. De letra de don Francisco de Oviedo una copia; otra de la del amanuense del autor.

20. Que se debe excusar la publicidad en los castigos de los que por vanidad los apetecen. Letra del amanuense de Quevedo.

54. La hora de tolos y la Fortuna con seso. Existe de letra del ananuense de Quevedo, revisada y atildada por el autor.

58. Premáticas contra las cotorreras. Copia del amanuense de Quevedo y por él revisada.

115. Cuento de cuentos. Existe el manuscrito original de letra del amanuense de Quevedo.

255. Entremés del marido pantasma. Letra del amanuense de Quevedo.

270. Anacreón castellano con paráfrasi y comentarios. De letra del amanuense de Quevedo ${ }^{22}$.

Hay aquí dos vertientes de análisis, una sobre el valor real de los distintos manuscritos, perfectamente localizados en algunos casos (como el del Anacreón castellano y el de La hora de todos, que hoy pertenece a Crosby), y otra sobre la coherencia interna del aparato textual esgrimido por Fernández Guerra. Aquí mi limito a la segunda vertiente. En las referencias que he copiado, la imagen de fidelidad al "original" se configuran suponiendo - suprema pericia paleográfica- revisiones, atildamientos y apostillas del autor sobre la escritura del amanuense ${ }^{23}$. Pero nada de esto se mantiene: la poca fe que el erudito tiene en la solidez de sus valoraciones le lleva a modificarlas sustancialmente cuando en otras ocasiones vuelve a filiar esos mismos textos. En su edición del Panegirico a Felipe $I V$, el amanuense se convierte en amanuenses y los dos manuscritos se hacen uno solo: "Poséelo el señor Durán, parte del leal amigo de nuestro autor, don Francisco de Oviedo, parte de letra de dos amanuenses del señor De la Torre de Juan Abad' (Ob-BAE, t. 1, p. 287). En el caso del Cuento de cuentos, el amanuense se esfuma, y el texto se edita según una "copia manuscrita contemporánea que, incompleta,

22 En el "Registro de los manuscritos que se han confrontado para la impresión" $(O b-B A E$, t. 2, p. xxxix) se agrega la Carta XXXIII como "de letra de amanuense de Quevedo (menos la cabeza que está escrita por Don Francisco)",

23 Hay que resaltar además que, como en el caso de los autógrafos, Fernández Guerra atribuía al amanuense piezas que representaban una novedad en el corpus quevediano (como la carta mencionada en la nota anterior, el Mundo caduco, el Panegírico, la refutación de Vasconcelos) o que pertenecían a su biblioteca o a la de sus amigos Pascual de Gayangos y Agustín Durán. 
posee la Academia de la Historia" (t. 2, p. 397): una copia que en el Registro se calificaba "de escaso mérito" (t. 2, p. xxxviii). Para Mundo caduco y desvarios de la edad, el cambio es aún más notable: el manuscrito deja de ser "de letra del amanuense de Quevedo"; ahora está hecho " a vista del original de Quevedo, mas por un amanuense tan rudo que ni entendió lo que escribió, ni supo descifrar la letra de Don Francisco, intrincada de suyo" (t. 1, p. 175). Por el contrario, el manuscrito de Su espada por Santiago, "autógrafo" según el Catálogo (t. 1, p. lxxxiii), y presentado en el Registro como "precioso manuscrito, de gallarda letra; el propio original que remitió nuestro autor al valido de Felipe IV para que lo pusiese en manos del monarca" (t. 2, p. xxxviii), a la hora de la edición pasa a ser obra del amanuense: "El original, de gallarda letra del amanuense de Quevedo con la firma autógrafa y evidentes señales de ser el propio memorial que hizo poner en manos del monarca" (t. 2, p. 423 ).

En el prisma de conocimientos de la moderna crítica textual, que especula sobre la existencia de manuscritos quevedianos debidos a un mismo copista y que busca apoyo documental para identificar en casos concretos un posible "amanuense", se ha filtrado sin duda la vieja concepción de Fernández Guerra, si bien él estaba lejos, naturalmente, de los refinamientos actuales. Él se limitó, de hecho, a ampliar con libertad y constancia cierta noticia sobre la existencia de "una peregrina colección que don Alfonso de Avellaneda hubo de formar con cuantas obras manuscritas hallaba de nuestro autor, autógrafas, apostilladas por él o de letra de su escribiente" (Ob-BAE, t. 1, p. 274). Ahí está ya la distinción entre la pluma del autor y la del amanuense. Y quien discriminó los productos de una y otra pluma fue uno de los grandes eruditos del siglo Xvm, "el ilustrado bibliotecario don Tomás Antonio Sánchez"; con qué criterios, lo desconocemos, tal como lo desconoció el propio Fernández Guerra, pues él no tuvo a la vista el cartapacio de Avellaneda, sino una copia de Sánchez, según confiesa al editar las Premáticas contra las cotorreras (t. 1, p. 431).

La necesidad de reconsiderar una y otra vez las tradiciones valorativas a que se han sometido las fuentes es una norma que pertenece a los rudimentos de la crítica textual, pero que no siempre se practica. Cuando el control se nos escapa, sobre todo en esa ardua empresa que es editar a Quevedo, las ambigüedades provocadas por la noción de "amanuense" pueden dar lugar a atribuciones erróneas, como la del Epitalamio de que aquí me he ocupado. 